\title{
Changes in Iron and Ferritin in Anemic Calves Infected with Theileria sergenti
}

\author{
Kiyotaka WATANABE, Masakazu OZAWA, Hironori OCHIAI, Hirokazu KAMOHARA, Noriko IIJIMA, \\ Hajime NEGITA, Kouichi ORINO and Shinji YAMAMOTO \\ Laboratory of Biochemistry, School of Veterinary Medicine and Animal Sciences, Kitasato University, Towada, Aomori 034-8628, \\ Japan
}

(Received 3 September 1997/Accepted 25 April 1998) ABSTRACT. Changes in iron and ferritin in calves infected with Theileria sergenti were investigated to elucidate iron metabolism in animals
with extravascular hemolytic anemia. During severe anemia, serum iron was remarkably elevated while the total iron-binding capacity
remained relatively unchanged or decreased slightly in the infected calves, resulting in elevated transferrin saturation. The serum ferritin
concentration gradually increased with the progress of anemia. The erythrocyte ferritin content drastically increased when mean
corpuscular volume was elevated. The concentration of non-heme iron and ferritin in the liver, spleen, and bone marrow of the infected
calves was markedly higher than that in the respective tissues of the control animals. In particular, the liver of the anemic calves was
found to contain 23 and 35 times as much non-heme iron and ferritin, respectively, as that of the non-anemic healthy cattle. The liver type
(L) to heart type $(\mathrm{H})$ subunit ratio of liver ferritin was significantly higher in the protozoa-infected than in the non-infected cattle. On the
other hand, the L/H ratio of marrow ferritin was significantly reduced by the anemia. These results indicate that the anemic calves
infected with $T$. sergenti apparently present symptoms of iron overload. - KEY worDs: anemia, calf, ferritin, iron, Theileria sergenti.

J. Vet. Med. Sci. 60(8): 943-947, 1998

Bovine theileriosis in Japan is caused by Theileria sergenti [14]. The main symptom of this disease is an anemia which may lead to death in severe cases. The erythrocytes of infected calves have been shown to exhibit increased osmotic fragility and deformity [25] and decreased survival [26]. Although the mechanism of the anemia in theileriosis has not been fully elucidated, erythrophagocytosis due to immune-mediated mechanisms may be responsible for the erythrocyte destruction [23], as in malaria [17] and in anaplasmosis [11]. Because hemoglobinuria is never observed even in seriously anemic calves infected with $T$. sergenti $[9,14]$, no substantial loss of body iron content in anemic animals is thought to occur. Under such circumstances, a relocation of iron, with decreases in circulating hemoglobin and reciprocal increases in stores, most likely occurs [22].

Iron metabolism in bovine theileriosis has yet to be examined. In the present study, changes in iron and an iron-storage protein, ferritin, in calves naturally infected with Theileria sergenti were investigated in order to elucidate the metabolism of iron in animals with extravascular hemolytic anemia.

\section{MATERIALS AND METHODS}

Experimental animals: Four clinically normal Holstein calves aged 5-6 months that had been found to be $T$. sergenti-free by blood smear examination described below were used in this experiment. Two calves (Nos. 1 and 2) were grazed for two weeks in a pasture contaminated with the tick vector of $T$. sergenti in the Shimokita region of Aomori prefecture for acquiring natural infection. After grazing, the infected calves were raised individually in pens for about 45 days. The two control calves were raised exclusively in pens. Blood samples were obtained every two or three days. Liver, spleen, and bone marrow were obtained when the calves were euthanized, and stored at $-20^{\circ} \mathrm{C}$ until use.

Routine blood examination: Red blood cell (RBC) counts, packed cell volume (PCV), mean corpuscular volume (MCV), hemoglobin concentration, mean corpuscular hemoglobin concentration (MCHC), and counts of parasitized erythrocytes detected in Giemsa-stained thin mears were routinely examined in blood samples.

Serum iron and total iron-binding capacity (TIBC): Serum iron and TIBC were determined coulometrically [19]. Transferrin saturation was defined and calculated as the percentage of serum iron in TIBC.

Tissue homogenates and extracts: The frozen tissue was slightly thawed and homogenized with 10 volumes of 10 $\mathrm{mM}$ Tris containing $0.1 \mathrm{mM}$ phenylmethylsulfonylfluoride in a Waring blender for $3 \mathrm{~min}$. Each homogenate was divided into two parts. One was used for measuring nonheme iron. The other was centrifuged at $24,000 \times \mathrm{g}$ for 20 min at $4{ }^{\circ} \mathrm{C}$, and the supernatant was used for the ferritin assay and immunoblotting.

Preparation of hemolysates: Leukocytes were removed from $1 \mathrm{~m} l$ of blood anticoagulated with EDTA according to the method of Beutler et al. [3]. The eluted erythrocytes were then washed three times with $0.154 \mathrm{M} \mathrm{NaCl}$ by centrifugation at $700 \times \mathrm{g}$. The cells were resuspended in 2 $\mathrm{m} l$ of $0.154 \mathrm{M} \mathrm{NaCl}$, and centrifuged once more at $700 \times \mathrm{g}$. Most of the supernatant $(1.5 \mathrm{ml})$ was discarded, and $1.5 \mathrm{~m} l$ of cold distilled water was added to the remaining cell pellet to lyse the red cells. The hemolysates were stored at $-20^{\circ} \mathrm{C}$ until ferritin analysis.

Assay of non-heme iron: Eight hundred microliters of 3 $\mathrm{M} \mathrm{HCl}$ was added to $400 \mu \mathrm{l}$ of tissue homogenate, and the 
mixture incubated for $48 \mathrm{hr}$ at $37^{\circ} \mathrm{C}$ with occasional agitation. The mixture was then centrifuged at $8,400 \times \mathrm{g}$ for $10 \mathrm{~min}$ at room temperature, and the released non-heme iron in the clear supernatant was measured coulometrically [19].

Enzyme-linked immunosorbent assay (ELISA): Except for red cell ferritin, ferritin in sera and tissue extracts was determined using a sandwich ELISA [12].

Immediately prior to assay, the above frozen hemolysates were thawed, and stroma was removed by centrifugation at $24,000 \times \mathrm{g}$ for $20 \mathrm{~min}$. Ferritin in the supernatant was assayed by an avidin-biotin complex (ABC) ELISA due to the relatively low concentration of ferritin in red cells. The ABC-ELISA was performed as follows. The microtiter plates were coated with the affinity-purified antibody to ferritin followed by washing and masking which were performed as for the sandwich ELISA [12]. Ferritin samples in $20 \mathrm{mM}$ sodium phosphate buffer containing $150 \mathrm{mM}$ $\mathrm{NaCl}, 0.1 \%$ gelatin, and $0.1 \%$ Tween $20, \mathrm{pH} 7.2(100 \mu l)$ were added to each well of the plates, which were then incubated at $37^{\circ} \mathrm{C}$ for $90 \mathrm{~min}$. After washing the plates, a $100 \mu l$ aliquot of $250 \mathrm{ng} / \mathrm{m} l$ biotinylated anti-ferritin antibody, which was prepared as previously described [6], was added to each well and the plates were incubated at $37^{\circ} \mathrm{C}$ for $90 \mathrm{~min}$. After washing, a $100 \mu \mathrm{l}$ aliquot of a mixture containing $4 \mu \mathrm{g} / \mathrm{m} l$ streptavidin (Sigma Chemical Co., U.S.A.) and $2 \mu \mathrm{g} / \mathrm{m} l$ biotinylated alkaline phosphatase (Zymed Laboratories, Inc., U.S.A.) was added and the plates incubated at $37^{\circ} \mathrm{C}$ for $60 \mathrm{~min}$. After washing, the enzyme reaction was performed as in the previously described sandwich ELISA method. The sensitivity limit of the assay was $0.1 \mathrm{ng} / \mathrm{ml}$.

Immunoblotting of tissue extracts: Sodium dodecyl sulfate polyacrylamide gel electrophoresis [24] of the above tissue extracts was performed using the buffer system of Laemmli [13] and a $12 \%$ polyacrylamide running gel. Immunoblotting [24] was performed using an affinitypurified antibody to bovine spleen ferritin [12] as the probe. The liver type $(\mathrm{L})$ to heart type $(\mathrm{H})$ subunit ratio of tissue ferritin was determined by densitometric scan of the blotting membrane at $535 \mathrm{~nm}$.

Statistical analysis: The dada were analyzed using the Student's $t$ test.

\section{RESULTS}

Figure 1 shows the changes in parasitemia and hematologic parameters in the Theileria sergenti-infected calves after the beginning of grazing. Neither Anaplasma nor Babesia infection was detected by blood smear examination. The infected animals showed macrocytic hypochromic anemia. Changes in serum iron, TIBC, and transferrin saturation in the infected animals are shown in Fig. 2. The serum iron concentration increased during rapid decline of PCV and RBC. The TIBC remained relatively unchanged or decreased slightly in the infected calves during severe anemia. Therefore, the transferrin saturation
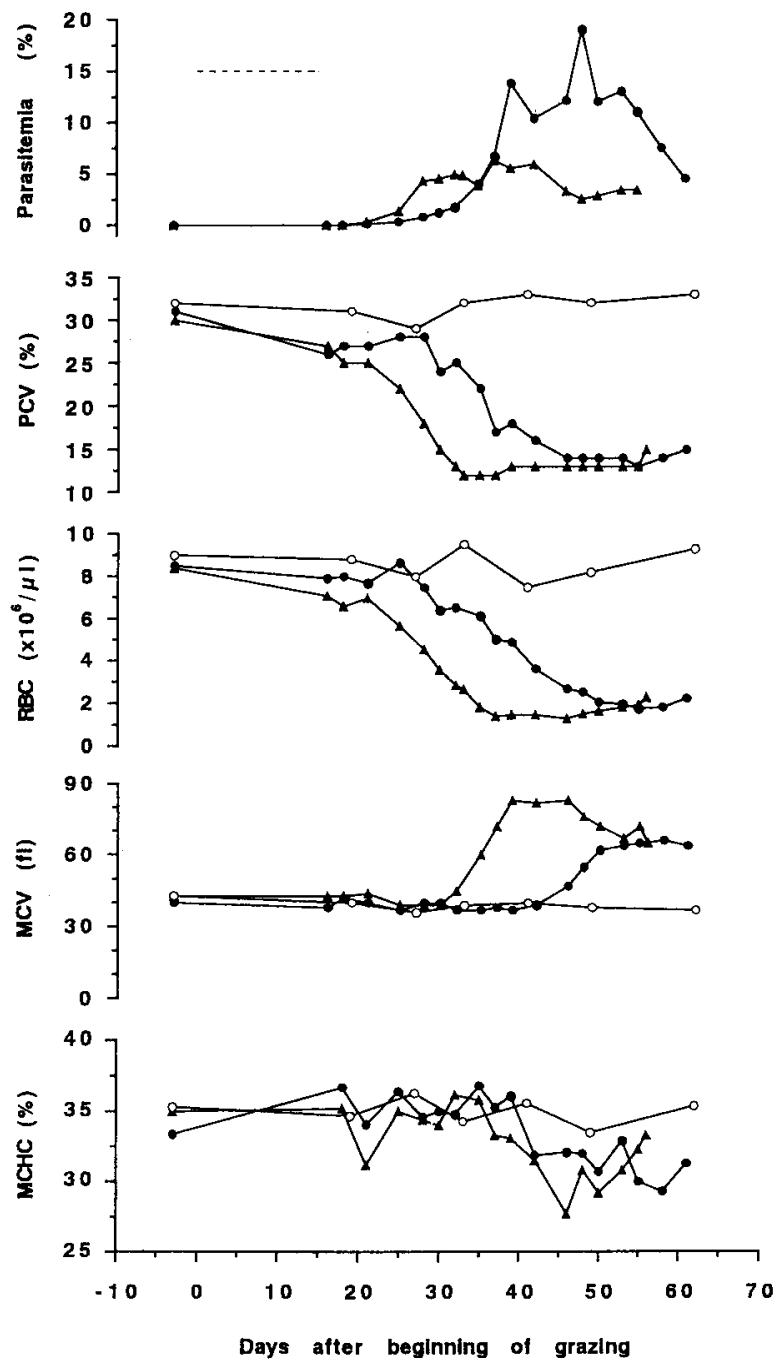

Fig. 1. Changes in parasitemia and hematologic parameters in Theileria sergenti-infected and control calves. $\boldsymbol{\Delta}$ and $\mathbf{O}$ : infected calves Nos. 1 and 2, respectively, $\bigcirc$ : mean of 2 control calves, ----: the period of grazing.

markedly increased and reached almost $100 \%$ during that period.

The mean serum and erythrocyte ferritin levels of two control calves varied somewhat during 65 days of the experimental period, but remained between 15 and $25 \mathrm{ng} /$ $\mathrm{m} l$ and between 0.20 and $0.32 \mathrm{ag} /$ cell, respectively (Fig. 3). In the Theileria sergenti-infected calves, the serum ferritin level gradually increased as anemia progressed and the RBC ferritin level drastically increased when the MCV was elevated (Figs. 1 and 3 ).

The infected calves Nos. 1 and 2 were euthanized 56 and 61 days, respectively, after the beginning of grazing, when their respective RBC counts were 2.29 and 2.25 million/ $\mu l$. The concentration of non-heme iron and ferritin in the major sites of iron storage, i.e., the liver, spleen, and bone marrow, of the infected calves was markedly higher than in the respective tissues of the control animals (Table 1). In 

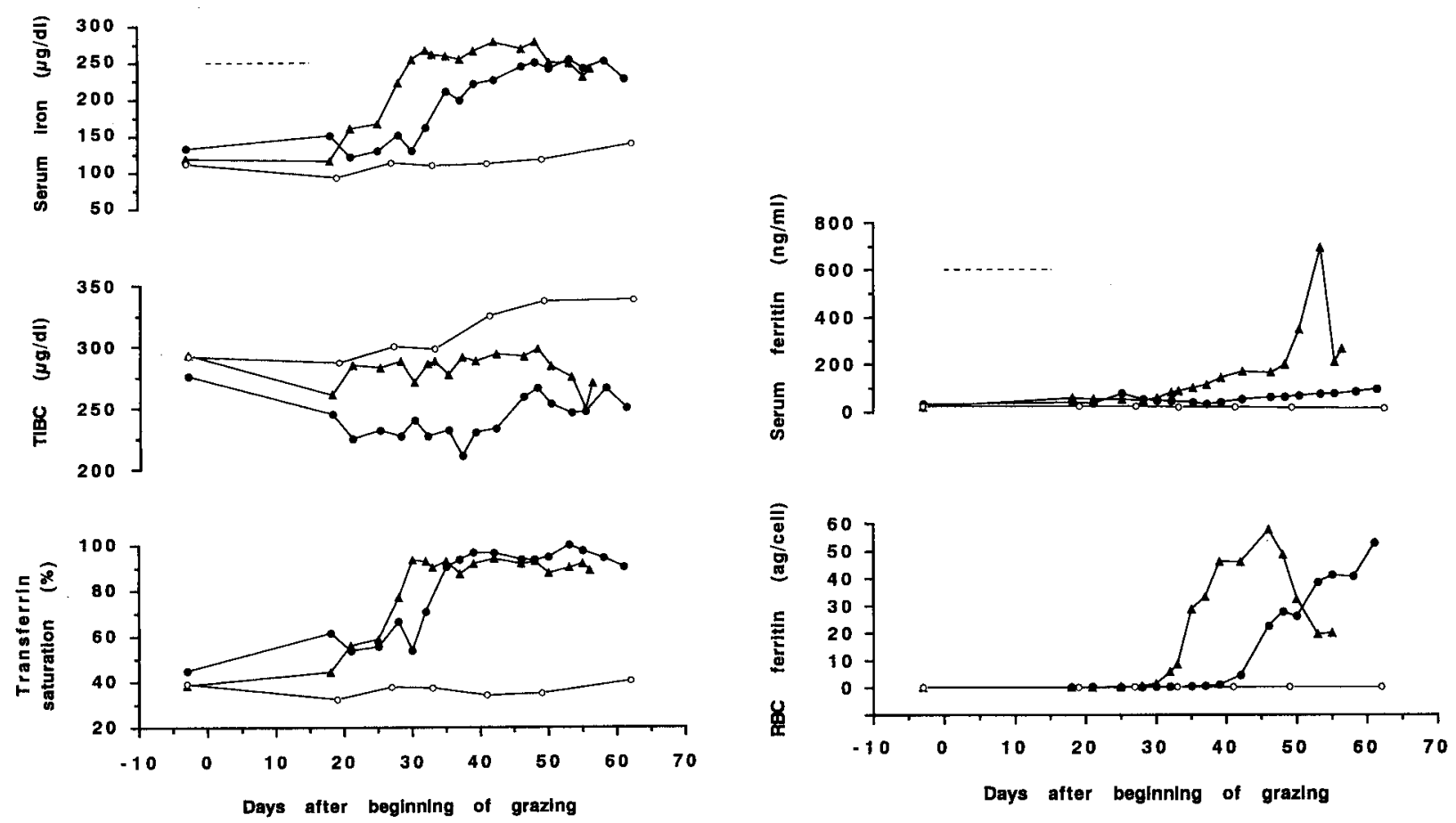

Fig. 2. Changes in serum iron, TIBC, and transferrin saturation in Theileria sergenti-infected and control calves. $\boldsymbol{\Delta}$ and infected calves Nos. 1 and 2, respectively, $\bigcirc$ : mean of 2 control calves, ----: the period of grazing.

Fig. 3. Changes in serum and RBC ferritin in Theileria sergenti-infected and control calves. $\boldsymbol{\Delta}$ and $\mathbf{O}$ : infected calves Nos. 1 and 2, respectively, $\bigcirc$ : mean of 2 control calves, ----: the period of grazing.

Table 1. Comparison of non-heme iron, ferritin, and ferritin $\mathrm{L} / \mathrm{H}$ subunit ratio in liver, spleen, and bone marrow between control and infected cattle

\begin{tabular}{|c|c|c|c|c|c|c|}
\hline & \multicolumn{2}{|c|}{ Liver } & \multicolumn{2}{|c|}{ Spleen } & \multicolumn{2}{|c|}{ Bone marrow } \\
\hline & Control & Infected & Control & Infected & Control & Infected \\
\hline Non-heme iron ${ }^{a)}$ & $30 \pm 6$ & $681 \pm 13^{* * *}$ & $268 \pm 93$ & $736 \pm 139$ & $29 \pm 3$ & $182 \pm 1 * * *$ \\
\hline Ferritina) & $48 \pm 1$ & $1664 \pm 71 * * *$ & $185 \pm 21$ & $503 \pm 21^{* *}$ & $29 \pm 3$ & $241 \pm 2 * * *$ \\
\hline Ferritin $\mathrm{L} / \mathrm{H}$ subunit ratio & $1.6 \pm 0.1$ & $2.8 \pm 0.3^{*}$ & $1.6 \pm 0.1$ & $1.7 \pm 0.1$ & $4.7 \pm 0.3$ & $1.9 \pm 0.4^{*}$ \\
\hline
\end{tabular}

a) $\mu \mathrm{g} / \mathrm{g}$ wet tissue. Values are expressed as mean $\pm \mathrm{SD}$. Asterisk indicates a significance of difference from control (*: $\mathrm{p}<0.05, * *$ : $\mathrm{p}<0.01, * * *: \mathrm{p}<0.001)$.

particular, the liver of the anemic calves was found to contain 23 and 35 times as much non-heme iron and ferritin, respectively, as that of the control cattle. The $\mathrm{L} / \mathrm{H}$ subunit ratio of the liver ferritin was significantly higher in the protozoa-infected than in the non-infected animals, whereas that of the marrow ferritin was significantly reduced by the anemia.

\section{DISCUSSION}

In the present study, elevated serum iron and transferrin saturation were found in anemic calves with theileriosis. In contrast, little increase in these parameters has been found in human [16] and rat [7] malaria. Hepatic non-heme iron was found in the present study to be markedly elevated in Theileria-infected calves, whereas there is no significant increase in hepatic non-heme iron in malaria-infected rats with anemia [7].

Ferritin is synthesized in all tissues and serves as an intracellular iron storage protein [21]. Ferritin is also present in serum and the level of circulating ferritin is directly related to body stores of iron [2, 10, 15]. Tissue ferritin injected into the vein is rapidly taken up by the liver, in which ferritin receptors are present [1]. Sibille et al. [18] demonstrated that isolated Kupffer cells are capable of releasing iron acquired by phagocytosis of immunosensitized homologous RBC in the form of ferritin, and that when reincubated with isolated hepatocytes, this released ferritin is rapidly taken up by the hepatocytes. These results suggest that ferritin may serve as an intrahepatic carrier of iron between Kupffer cells and hepatocytes. In addition, ferritin is thought to be released in vivo by splenic macrophages after erythrophagocytosis and delivered to the liver via portal circulation. In the present study, the non-heme iron 
concentration in the liver was markedly elevated in calves infected with $T$. sergenti. Therefore, in bovine theileriosis, the excess iron processed by erythrophagocytosis in the liver and spleen may be stored mainly in hepatocytes through such mechanisms as described above. The elevated serum ferritin level in the $T$. sergenti-infected cattle is considered to reflect apparently increased body iron stores [2, 10, 15].

The protein shells of tissue ferritin consist of two subunit species (liver (L) and heart $(\mathrm{H})$ ) in proportions varying according to the tissue and its iron content $[4,21]$. Studies on the effect of liver iron content on the liver ferritin $\mathrm{L} / \mathrm{H}$ subunit ratio revealed that $\mathrm{L}$-subunit-rich ferritin has a preferential capacity for iron storage [4]. In agreement with this finding, in the present study the proportion of $\mathrm{L}$ to $\mathrm{H}$ in liver ferritin was elevated with the increased liver iron stores in the protozoa-infected anemic cattle.

Two factors appear to be important in determining the red cell ferritin content: (1) the transferrin saturation and (2) the rate of hemoglobin synthesis [5]. Because the erythroblasts from subjects with high transferrin saturation take up more iron than that required for heme synthesis, excess iron in the cells is stored in ferritin molecules, thus producing increasing amounts of $\mathrm{RBC}$ ferritin. If hemoglobin synthesis is impaired even in subjects with normal iron status and normal transferrin saturation, excess iron in the erythroblasts results in a high $\mathrm{RBC}$ ferritin content. In the present study, the $T$. sergenti-infected calves showed hypochromic anemia, indicating reduced hemoglobin synthesis. Therefore, the elevated erythrocyte ferritin level in the protozoa-infected calves can be explained both by high transferrin saturation and by a decrease in the rate of hemoglobin synthesis.

$\mathrm{H}$-subunit-rich ferritin is known to be predominant in immature red cells in the bone marrow, particularly in proerythroblasts and basophilic erythroblasts, whereas Lsubunit-rich ferritin is predominant in reticuloendothelial cells [8]. Furthermore, the body iron status affects the erythroblast ferritin content, which is reduced in iron deficiency and increased in iron overload [8]. The elevated non-heme iron and ferritin levels in the bone marrow of the Theileria-infected calves in the present study appear to have resulted from increased body iron stores. The decreased L/ $\mathrm{H}$ subunit ratio of the marrow ferritin of the infected animals is considered to reflect enhanced erythropoiesis as observed previously by Takahashi et al. [20].

ACKNOWLEDGMENTS. We are grateful to Dr. Seiichi Kawamura for his invaluable advice. This study was supported in part by a Grant-in-Aid for Scientific Research (C) from the Ministry of Education, Science and Culture of Japan (No. 06660411).

\section{REFERENCES}

1. Adams, P. C., Powell, L. W. and Halliday, J. W. 1988. Isolation of a human hepatic ferritin receptor. Hepatology 8: 719-721.
2. Addison, G. M., Beamish, M. R., Hales, C. N., Hodgkins, M., Jacobs, A. and Llewellin P. 1972. An immunoradiometric assay for ferritin in the serum of normal subjects and patients with iron deficiency and iron overload. J. Clin. Pathol. 25: 326-329.

3. Beutler, E., West, C. and Blume, K.-G. 1976. The removal of leukocytes and platelets from whole blood. J. Lab. Clin. Med. 88: 328-333.

4. Bomford, A., Conlon-Hollingshead, C. and Munro, H. N. 1981. Adaptive responses of rat tissue isoferritins to iron administration. Changes in subunit synthesis, isoferritin abundance, and capacity for iron storage. J. Biol. Chem. 256: 948-955.

5. Cazzola, M., Dezza, L., Bergamaschi, G., Barosi, G., Bellotti, V., Caldera, D., Ciriello, M. M., Quaglini, S., Arosio, P. and Ascari, E. 1983. Biologic and clinical significance of red cell ferritin. Blood 62: 1078-1087.

6. Costello, S. M., Felix, R. T. and Giese, R. W. 1979. Enhancement of immune cellular agglutination by use of an avidin-biotin system. Clin. Chem. 25: 1572-1580.

7. Hershko, C. and Peto, T. E. A. 1988. Deferoxamine inhibition of malaria is independent of host iron status. J. Exp. Med. 168: 375-387.

8. Invernizzi, R., Cazzola, M., De Fazio, P., Rosti, V., Ruggeri, G. and Arosio, P. 1990. Immunocytochemical detection of ferritin in human bone marrow and peripheral blood cells using monoclonal antibodies specific for the $\mathrm{H}$ and $\mathrm{L}$ subunit. Br. J. Haematol. 76: 427-432.

9. Ishihara, T. 1968. Bovine piroplasmosis in Japan. Jpn. Agric. Res. Q. 3: 23-31.

10. Jacobs, A., Miller, F., Worwood, M., Beamish, M. R. and Wardrop, C. A. 1972. Ferritin in the serum of normal subjects and patients with iron deficiency and iron overload. $\mathrm{Br}$. Med. J. 4: 206-208.

11. Jain, N. C. 1986. Hemolytic anemia associated with some infectious agents. pp. 589-626. In: Schalm's Veterinary Hematology, 4th ed., Lea and Febiger, Philadelphia.

12. Kakuta, K., Orino, K., Yamamoto, S. and Watanabe, K. 1997. High levels of ferritin and its iron in fetal bovine serum. Comp. Biochem. Physiol. 118A: 165-169.

13. Laemmli, U. K. 1970. Cleavage of structural proteins during the assembly of the head of bacteriophage T4. Nature (Lond.) 227: 680-685.

14. Minami, T., Fuginaga, T., Furuya, K. and Ishihara, T. 1980. Clinico-hematologic and serological comparison of Japanese and Russian strains of Theileria sergenti. Natl. Inst. Anim. Health Q. (Tokyo) 20: 44-52.

15. Miyata, Y. and Furugouri, K. 1987. The relationship between serum ferritin concentration and tissue non-heme iron or tissue ferritin in dairy cattle. Jpn. J. Vet. Sci. 49: 1157-1159.

16. Phillips, R. E., Looareesuwan, S., Warrell, D. A., Lee, S. H., Karbwang, J., Warrell, M. J., White, N. J., Swasdichai, C. and Weatherall, D. J. 1986. The importance of anaemia in cerebral and uncomplicated falciparum malaria: role of complications, dyserythropoiesis and iron sequestration. Q. J. Med. 58: 305-323.

17. Rosenberg, E. B., Strickland, G. T., Yang, S. and Whalen, G. E. 1973. IgM antibodies to red cells and autoimmune anemia in patients with malaria. Am. J. Trop. Med. Hyg. 22: 146152.

18. Sibille, J.-C., Kondo, H. and Aisen, P. 1988. Interactions between isolated hepatocytes and Kupffer cells in iron me- 
tabolism: a possible role for ferritin as an iron carrier protein. Hepatology 8: 296-301.

19. Smith, J. E., Moore, K. and Schoneweis, D. 1981. Coulometric technique for iron determinations. Am. J. Vet. Res. 42: 1084-1085.

20. Takahashi, K., Yasuda, Y. and Murakami, D. 1973. Clinical and hematological changes in cattle experimentally infected with small-sized piroplasma. J. Jpn. Vet. Med. Assoc. 26: 279-284 (in Japanese with English abstract).

21. Theil, E. C. 1987. Ferritin: structure, gene regulation, and cellular function in animals, plants, and microorganisms. Аnnи. Rev. Biochem. 56: 289-315.

22. Torrance, J. D. and Bothwell, T. H. 1980. Tissue iron stores. Methods Hematol. 1: 90-115.
23. Uilenberg, G. 1981. Theileria infections other than east coast fever. Curr. Top. Vet. Med. Anim. Sci. 6: 411-427.

24. Watanabe, K., Yahikozawa, S., Orino, K. and Yamamoto, S. 1995. Immunological cross-reaction between lactoferrin and transferrin. J. Vet. Med. Sci. 57: 519-521.

25. Yagi, Y., Furuuchi, S., Takahashi, H. and Koyama, H. 1989. Abnormality of osmotic fragility and morphological disorder of bovine erythrocytes infected with Theileria sergenti. Jpn. J. Vet. Sci. 51: 389-395.

26. Yagi, Y., Ito, N. and Kunugiyama, I. 1991. Decrease in erythrocyte survival in Theileria sergenti-infected calves determined by non-radioactive chromium labelling method. J. Vet. Med. Sci. 53: 391-394. 